\title{
Mitigate PAPR Effect in Optical Orthogonal Frequency Division Multiplexing Using Companding Technique
}

\author{
Ali n. Kareem ${ }^{1}$, Sinan M. Abdul Satar ${ }^{2}$, Mohammed A. Husein ${ }^{3}$ \\ Department of Electrical Engineering, University of Technology, Baghdad, Iraq, \\ alinkareem@yahoo.com,sinansma@yahoo.com,mfzay@yahoo.com
}

\begin{abstract}
OFDM) is emerging as the leading technology for high data rates. The OFDM based on multicarrier transmission that transforms a wideband channel into a group of thin-band channels. The high peak to average power ratio (PAPR) considers the main drawback factor in this system, so the companding technique modifies the amplitude of OFDM signal to reduce this factor. The proposed A-law companding technique has been implemented in intensity modulation/direct detection optical orthogonal frequency division multiplexing (IM/DDOOFDM). The proposed companding scheme guarantees the improved performance in terms of bit error rate (BER) and quality factor (QF) while reducing PAPR effectively and efficiently by modifying the amplitude of the transmitted signals. Our results confirm that the suggested scheme exhibits a good ability to reduce PAPR and a good BER performance based on the use the A factor. At the complementary cumulative distribution function (CCDF) of 10 3 , the PAPR value of our proposed scheme is about $4.4 \mathrm{~dB}$ lower than those of un-companded signal at best control factor used of $A$ at 87.6, accordingly the $\mathrm{QF}$ is $2.5 \mathrm{~dB}$ and the $\mathrm{BER}$ is $6.2 \times 10^{-3}$ at a distance $900 \mathrm{~km}$ without any equalization technique or training sequence or any channel estimation.
\end{abstract}

Index Terms- Orthogonal Frequency Division Multiplexing (OFDM), Peak-to-Average Power Ratio (PAPR), Intensity Modulation/Direct Detection Optical Orthogonal Frequency Division Multiplexing (IM/DD OOFDM), complementary cumulative distribution function (CCDF).

\section{INTRODUCTION}

An OFDM has been used in the optical communication systems because of its opposition to Intersymbol Interference (ISI) and high spectral efficiency. IM/DD OOFDM system has been extensively explored in long-haul optical Communications systems [1-3].

As well as its many advantages, OOFDM systems have several disadvantages such as ISI and PAPR [4]. The high power amplifier working in the nonlinear section, therefore, In-band and out-of-band interferences are increased due to this nonlinearity. At last, the performance of the transmitter is enhanced by using PAPR reduction techniques [5]. Several methods have been investigated to decrease PAPR of OFDM signals such as clipping, pre-coding, companding, selective-mapping (SLM) and partial-transmission-sequence [6-7]. These techniques used to decrease PAPR, but there are some drawbacks. A clipping is the simplest one and is widely active for real-time implementation, but it causes additional clipping noise that degrades system's performance. The clipping causes both in-band distortion and out-of-band distortion [6]. partial transmission technique [7-8], selective mapping [8-9] methods add extra complexity, coding complexity, or require extra optical components. 
Due to increases in bandwidth and large memory with complexity in these techniques so the companding technique is useful for PAPR to overcome this constraint [9 -10].

The OOFDM signal involves severally modulated subcarriers that may provide a large PAPR once value-added up coherently. An OOFDM signal features a massive PAPR that is terribly sensitive to the non-linearity of the high peak [3]. Blocks of the symbol in the "OFDM" are selected with every symbol modulating one from a set of subcarriers and these subcarriers are recognized to be orthogonal [11].

The representation of complex OFDM signal is:

$x(k)=\frac{1}{N} \sum_{n=0}^{N-1} X_{n} e^{\frac{j 2 \pi n k}{N}}$

Where $\mathrm{K}=0,1,2, \ldots, \mathrm{N}-1$

In this paper, due to large PAPR and low complexity, the propose A-law companding transform are using to mitigate the non-linearity that comes from PAPR by reduction this factor. The rest of the paper is organized as follows. In Section 2, a brief description of PAPR in an OFDM system. In Section 3, the definition of A-law companding reduction technique. In Section 4, descriptions of the proposed system, with A-law transform. In Section 5 results and discussion of the proposed system. in Section 6 conclusion with suggestions for further work.

\section{PEAKS-TO-AVERAGE POWER RATIO (PAPR)}

The PAPR for a signal $\mathrm{x}(\mathrm{K})$ is outlined as the ratio of maximum instantaneous power to the average power [10] as below:

$$
P A P R=10 * \log \left(\frac{\max |x(k)|^{2}}{\operatorname{Avg}|x(k)|^{2}}\right)
$$

Reduction of PAPR simply shows the probabilities that the PAPR of data block exceeds the given threshold value [11]. The expression of the CCDF is:

$$
\mathrm{CCDF}=\text { Probability }\left(\mathrm{PAPR}>\mathrm{PAPR}_{\mathrm{th}}\right)
$$

Where PAPR th represents the Threshold level.

\section{A-LAW COMPANDING TECHNIQUE}

Due to low complexes irrespective of the number of subcarriers, therefore the companding technique for PAPR reduction in OFDM systems is used [4]. A-law is done at the transmitter as a compressor after IFFT and an expander before FFT at the receiver [12].

The A-law has a non-zero value and it has mid risen at the origin point [12] as shown in Fig. 1. The high-level inputs the appearances are logarithmic segmented and for lowlevel inputs, the appearances are linearly segmented [13]. 


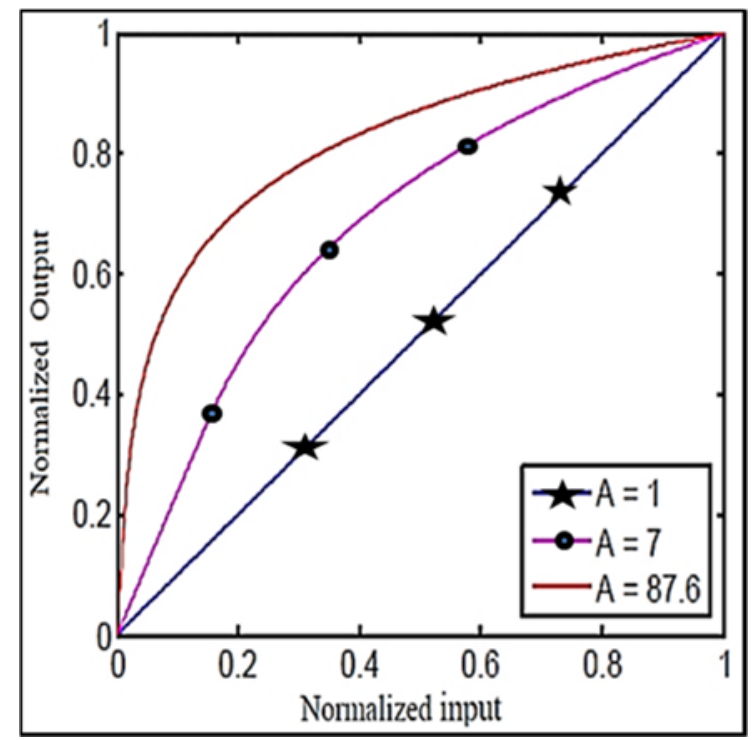

Fig. 1 CHARACTERISTICS OF A - LAW COMPRESSOR [5].

\section{THE PROPOSED MODELING SYSTEM OF COMPANDING TECHNIQUE IN IM/DD OOFDM}

Firstly, the typical configuration of OOFDM system without using companded technique is showing in fig. 2 a generic OOFDM systems, containing 5 basic blocks: OFDM transmitter, optical upconverter, an optical link, optical downconverter, and OFDM receiver[14,15].

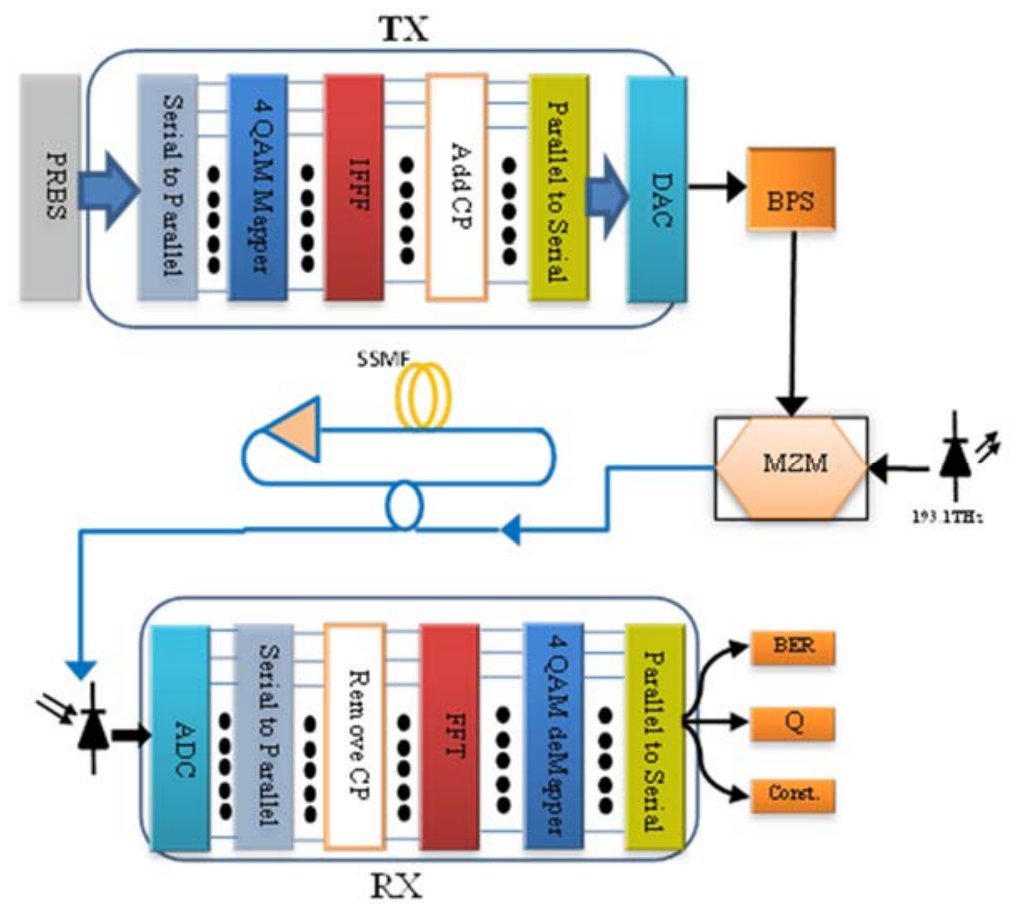

FIG. 2 THE TRADITIONAL OOFDM SYSTEM.

For the proposed modeling system as compared with the traditional system, the A-Law transforms is applied after the IFFT at transmitter prior to before in receiver the as shown in fig. 3. 


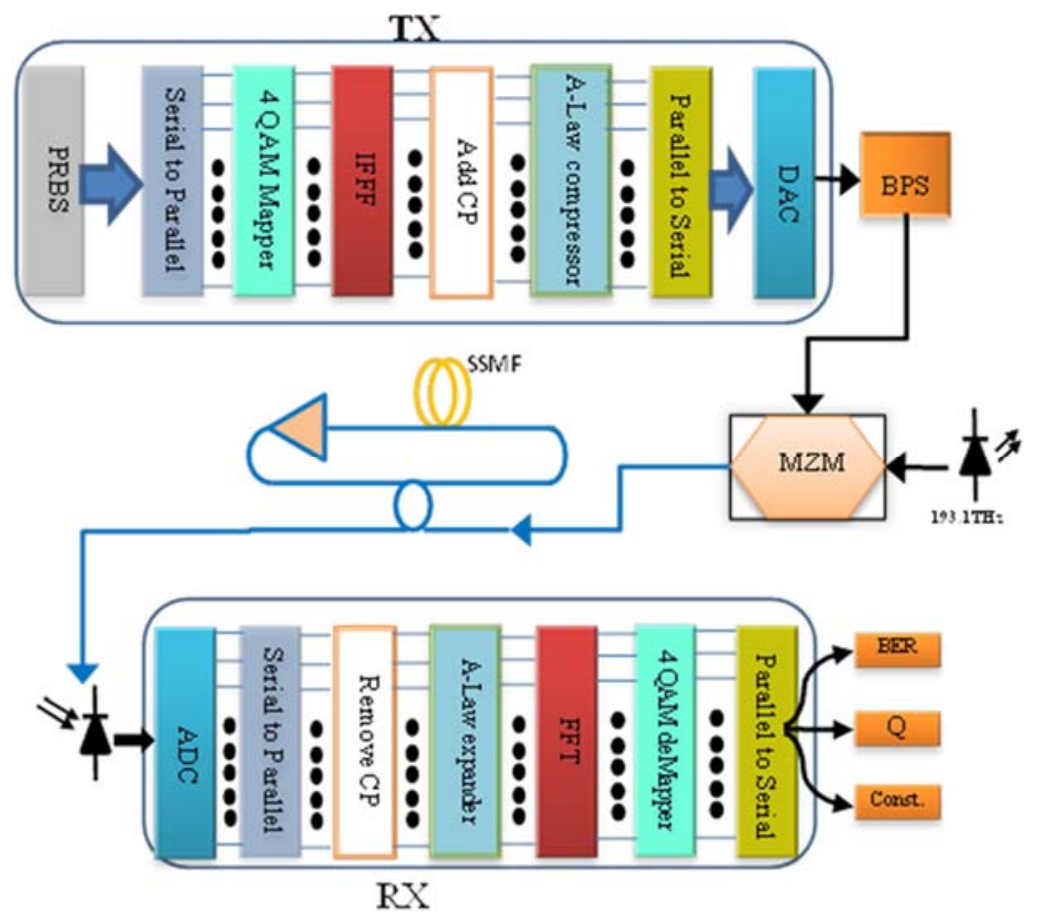

FIg. 3 OOFDM SYSTEM USING PROPOSED A- LAW COMPANDING TECHNIQUE.

On the transmitter side, the transmission bit rate is 10 Gbps. The bit streams are created using a pseudo-random binary sequence generator and the data are modulated by a 4QAM encoder. The information stream is further parsed into 128 parallel data subcarriers and processed by the IFFT processor. Accordingly, Table (1) summarizes the required parameter to implement the laser and channel performance.

TABLE .1. SIMULATION PARAMETERS FOR PROPOSED OOFDM

\begin{tabular}{cc|cc}
\hline \multicolumn{2}{c|}{ Global parameters } & \multicolumn{2}{c}{ Optical Link } \\
\hline BitRate & $10 \mathrm{Gbps}$ & SMF length & $50 \mathrm{~km}$ \\
Sample Rate & $40 \mathrm{Gbps}$ & DCF length & $10 \mathrm{~km}$ \\
Sequence length & 8192 & Number of loop & 15 \\
Bits per symbol & 2 & Attenuation for SMF & $0.2 \mathrm{~dB} / \mathrm{km}$ \\
OFDM modulator & Attenuation for DCF & $0.5 \mathrm{~dB} / \mathrm{km}$ \\
Max subcarriers & 128 & Dispersion SMF & $16 \mathrm{ps} / \mathrm{nm} / \mathrm{km}$ \\
Cyclic Prefix & $1 / 8$ & Dispersion DCF & $-80 \mathrm{ps}$ \\
CW Laser & & CoreArea of SMF & $80 \mu \mathrm{m}^{2}$ \\
Carrier & $193.1 \mathrm{THz}$ & CoreArea of DCF & $50 \mu \mathrm{m}^{2}$ \\
Frequency & $10 \mathrm{mw}$ & optical amplifier gain & $12 \mathrm{dBm}$ \\
Power & $0.1 \mathrm{MHz}$ & optical amplifier Noise & $4 \mathrm{dBm}$ \\
Line Width & figure & \\
\hline
\end{tabular}

The OFDM data was produced and decoded by MATLAB, and VPI_Transmission_Maker did the up-down optical conversion and fiber link. At the receiver, the reverse operation is applicable to pick up the original signal that's transmitted before. 


\section{RESULTS AND DISCUSSION}

The transmitted digital bit streams are originated in VPI_Transmission_Maker from the Pseudorandom binary sequence (PRBS) at $\left(2^{13}\right)$ and then OFDM data decoded with and without A-Law transform by Matlab software package, then optical modulation and optical up_conversion, transmission and downconversion are done by VPI_Transmission_Maker.

The coded OFDM signal (real and imaginary part of companded OFDM) is up-converted at $7.5 \mathrm{GHz}$ an intermediate frequency (IF) as shown in fig. 4.

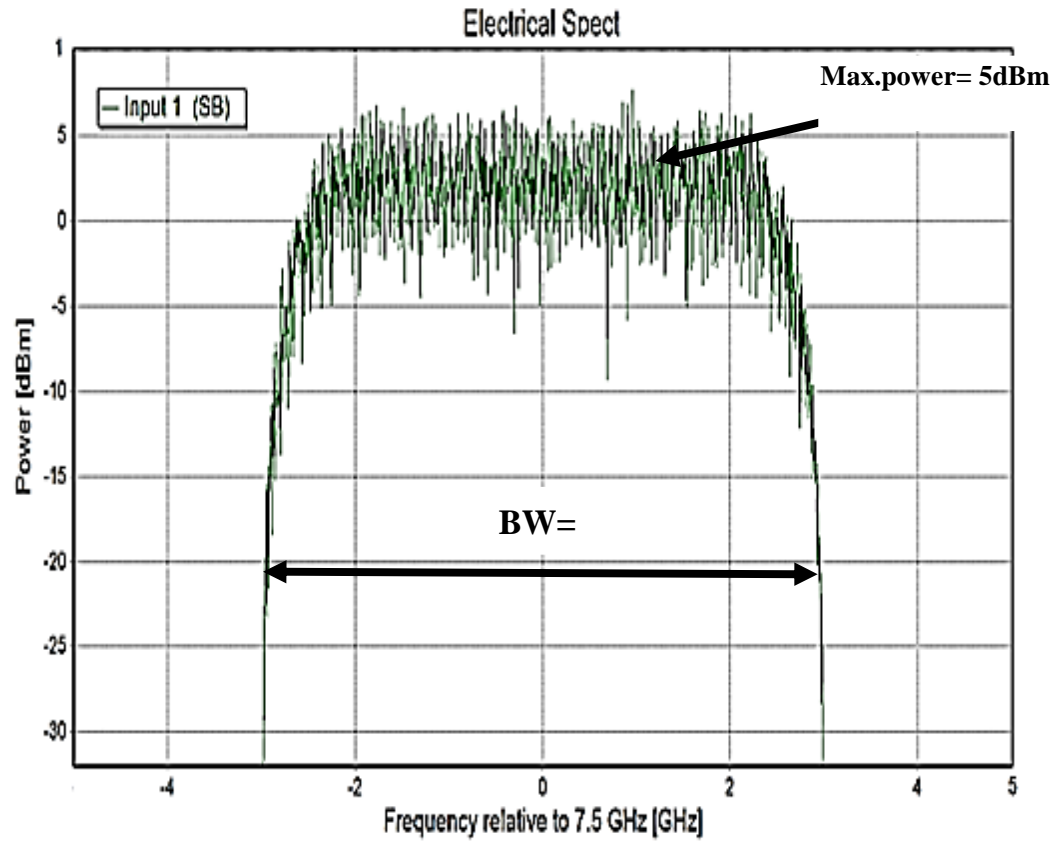

Fig. 4 Proposed Electrical OFDM SpeCtrum at IF=7.5GHz

The output spectrum power from MZM will contain an optical carrier which in this case is targeted at 193.1 THz with two side-bands targeted at $7.5 \mathrm{GHz}$ of the optical OFDM signal as displayed in fig. 5 .

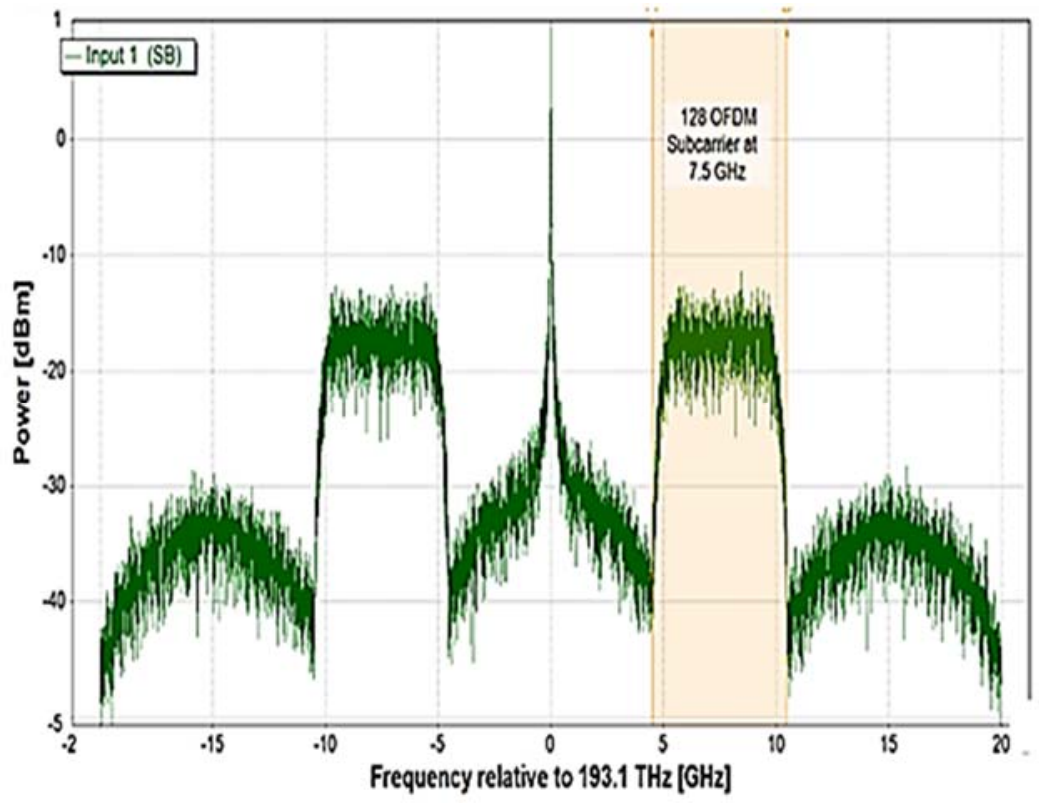

FIg. 5 THE SPECTRUM OF THE PROPOSED A-LAW OOFDM 
Likewise, an optical filter is then responsible for suppressing the lower side-band by $18 \mathrm{GHz}$ bandpass optical filter. The filtered OOFDM single shown in fig. 6 .

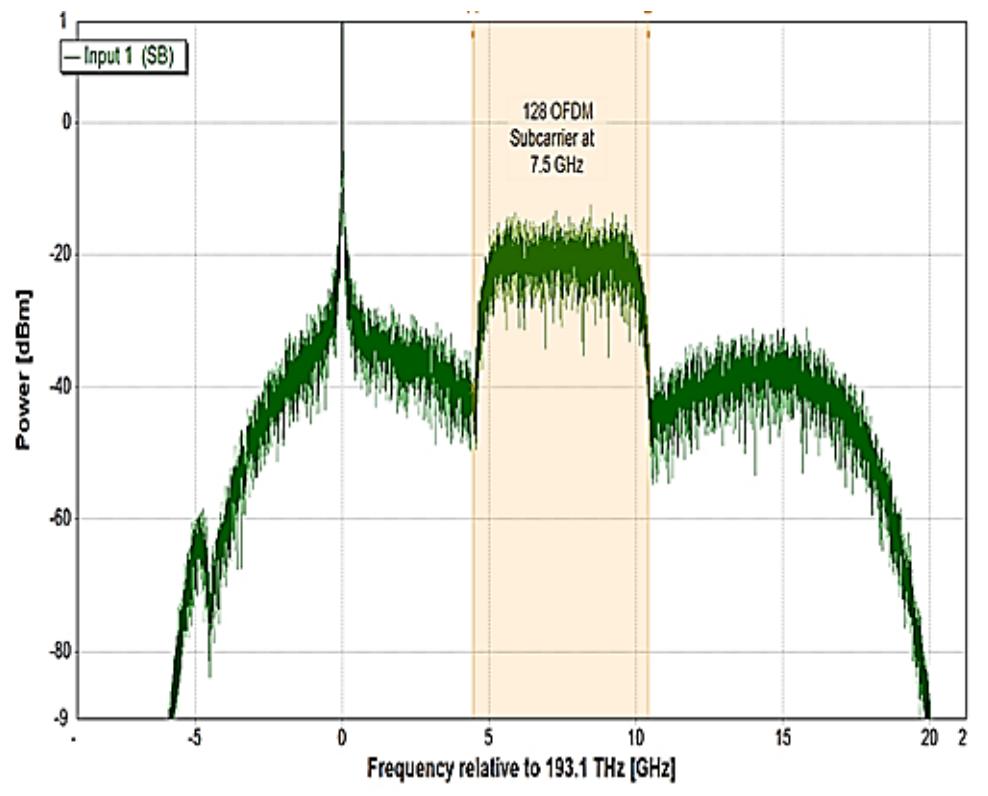

Fig. 6 THE SPECTRUM OF THE PROPOSED A-LAW OOFDM AFTER FILTERING.

Fig. 7 summarizes the PAPR performance of the proposed OOFDM transmitter is significantly more improved because of the controlling factor (A ) where he is get increasing reach to an optimum value, the more compression added in the transmitter with reverses in receiver side to mitigate the effect of the PAPR. Therefore, the transmitted signals have uniform distribution with less power to save it from high dispersion that was resulted from traveling through link. The PAPR of the proposed technique at $\mathrm{CCDF} \approx 10^{-3}$ is reduced by $2.2 \mathrm{~dB}$ at $\mathrm{A}=30$ and $4.45 \mathrm{~dB}$ at $\mathrm{A}=87.6$ as compared with the original signal.

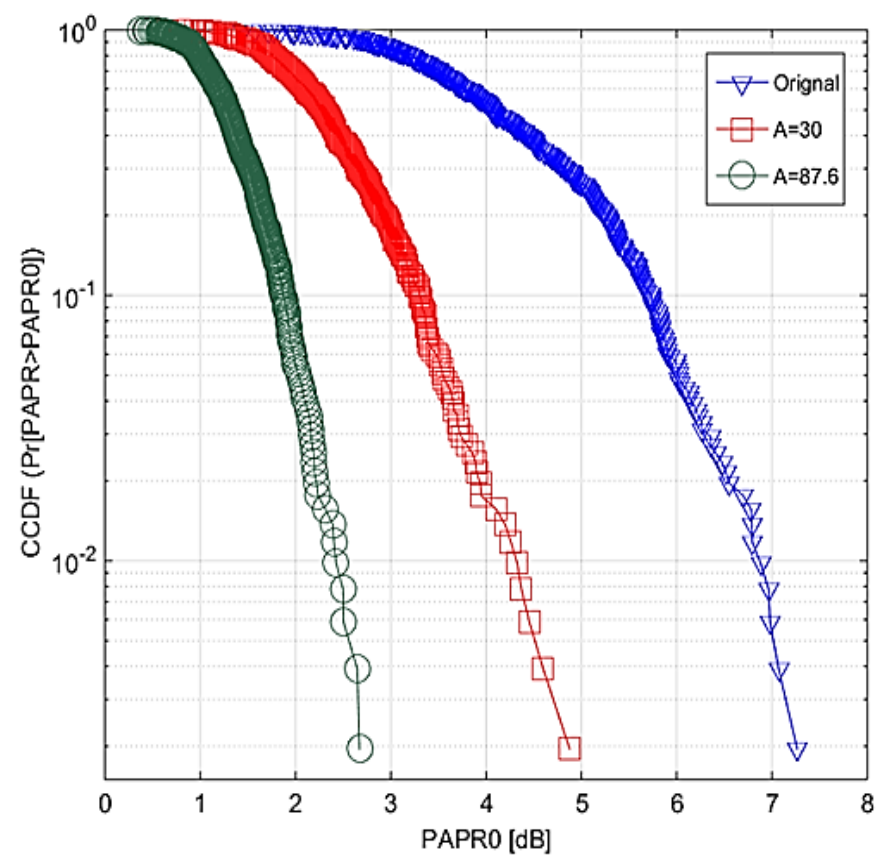

Fig. 7 CCDF PLOT IS SHOWING A-LAW PAPR REDUCTION 
The propose A-Law transform algorithm has been clearly enhanced the performance of all transmitter systems of OOFDM as shown in the constellation diagram in fig. 8 with two value of factor A at 30 and 87.6.

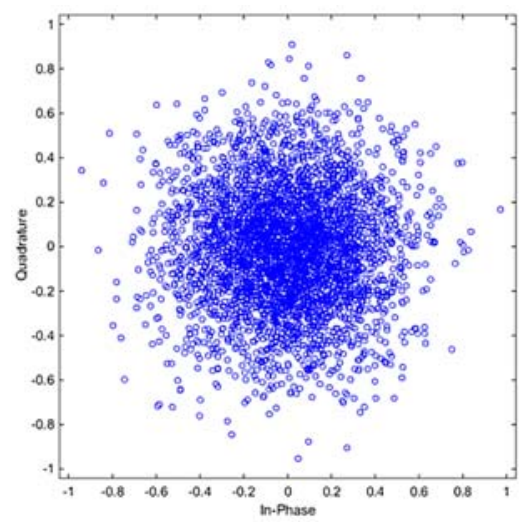

(a)

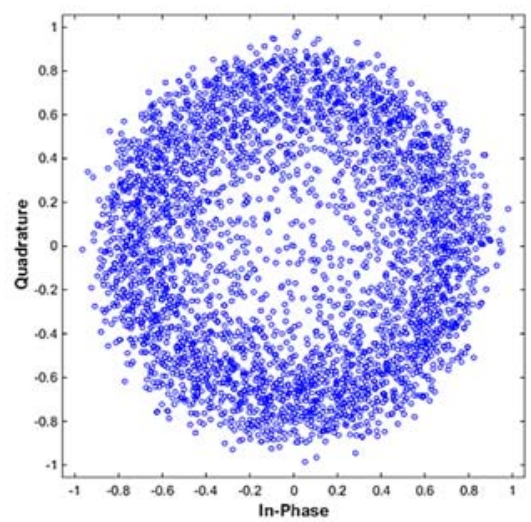

(b)

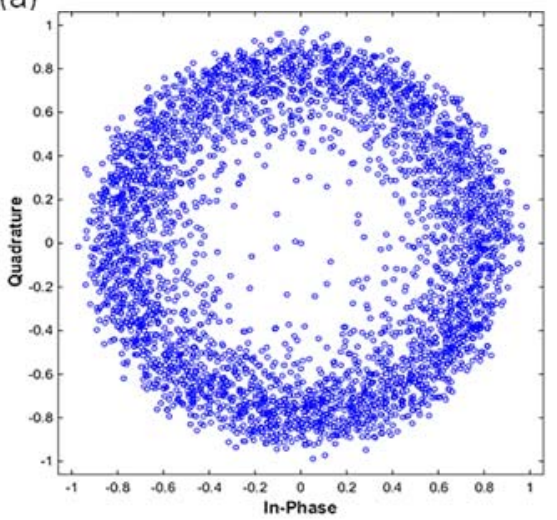

(c)

Fig. 8 CONSTELLATION DiAgRAM OF OOFDM AT END OF TX AT (A) ORIGINAL (B) PROPOSED COMPANDiNG AT A=30 (C) PROPOSED COMPANDING AT A=87.6

After the fiber length at $900 \mathrm{Km}(60 \mathrm{Km} \times 15)$ with 4 QAM modulation format The QF, BER and constellation diagram at the end of the receiver are shown in fig. 9, fig. 10 and fig. 11 respectively. Moreover, the degradation observed in the original system without companded technique used is shown in fig. 9, fig. 10 plotted with black color and fig. 11(a), the measured QF is $2 \mathrm{~dB}$, BER is $2.4 \times 10^{-1}$ and non-uniform constellation diagram. The degradation is the maximum because of the increasing of the chromatic dispersion when increasing the transmission length.

Mostly, the proposed A-Law algorithm clearly improves the OOFDM system performance described as QF, BER, and constellation diagram that presented in fig.9, fig.10, and fig.11. In this system, proposed two values of $A$ at 30 and 87.6 , the $A$ at 87.6 is totally enhancing the all system in term of $\mathrm{QF}$ at $2.5 \mathrm{~dB}$ and $\mathrm{BER}$ at $6.2 \times 10^{-3}$ than that using $\mathrm{A}$ at 30 which $\mathrm{QF}=1.4 \mathrm{~dB}$ and $\mathrm{BER}=2.9 \times 10^{-}$ 2 . 


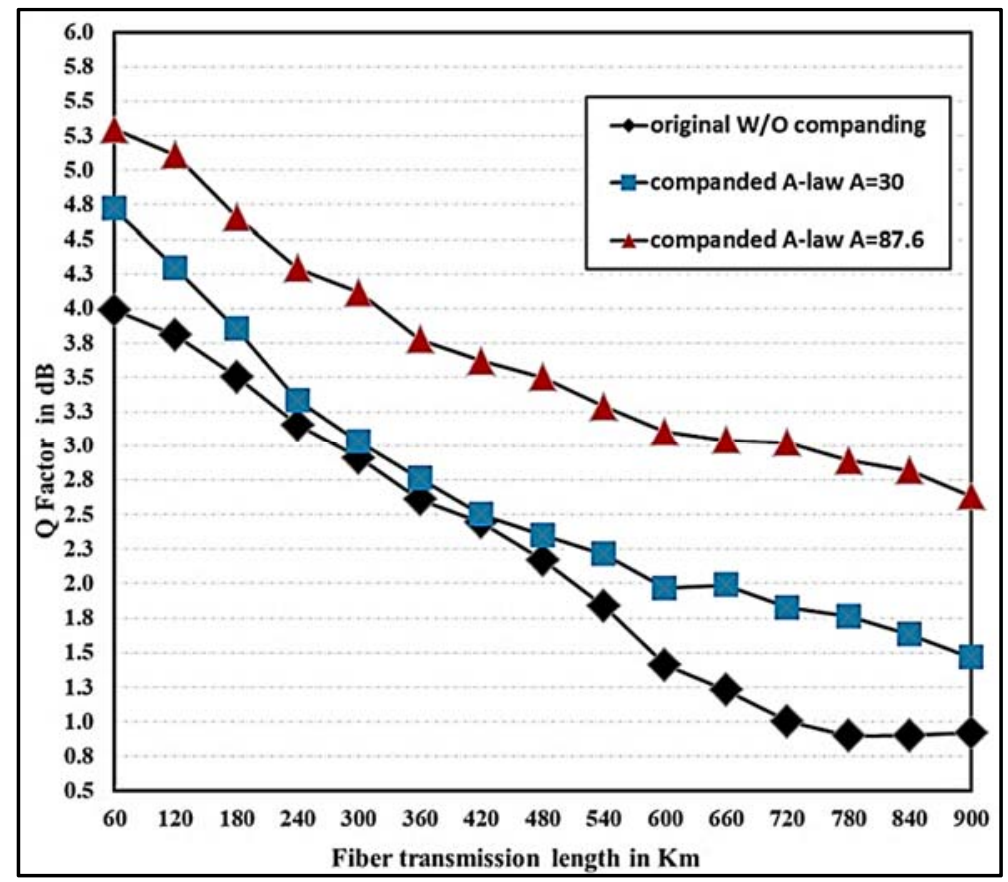

FIG. 9 QF VS FIBER LENGTH

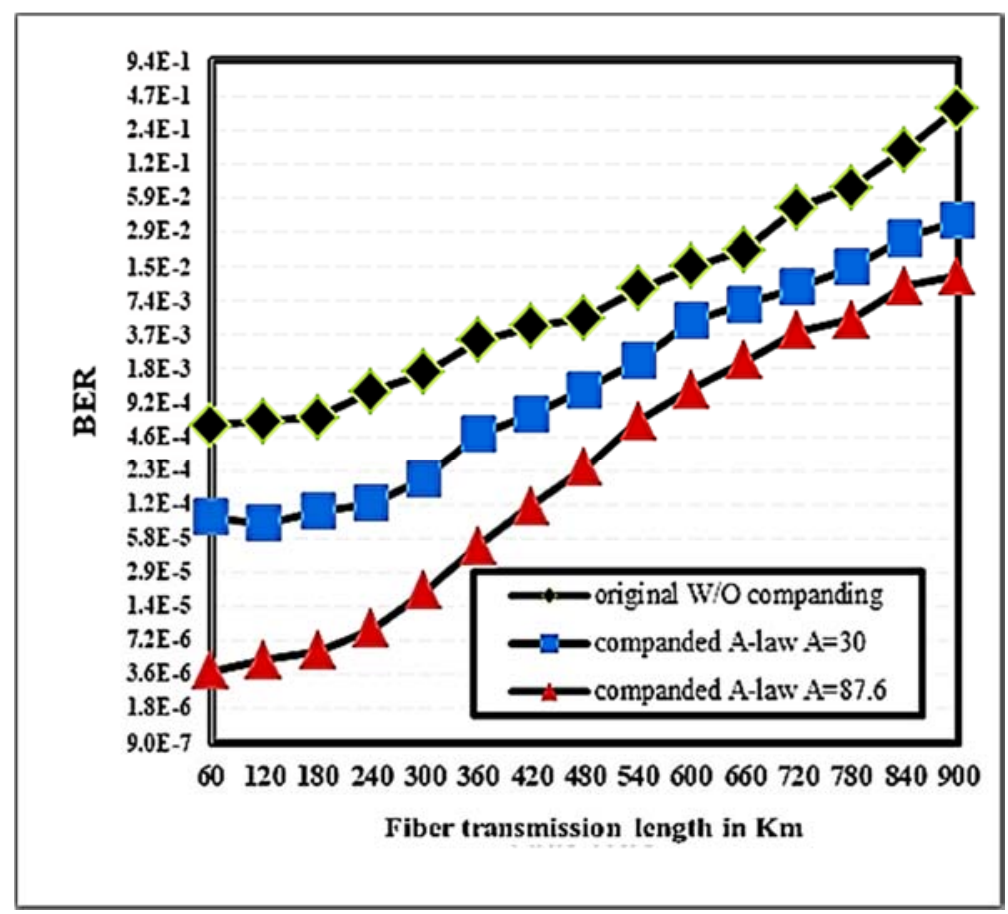

FIG. 10 BER VS FIBER LENGTH

Clearly as shown in fig. 11, the constellation performance is clearly the difference between the original and proposed technique. However, the control factor $\mathrm{A}$ at 87.6 a significant improvement in constellation performance over un-companded or companded at 30 of A. 


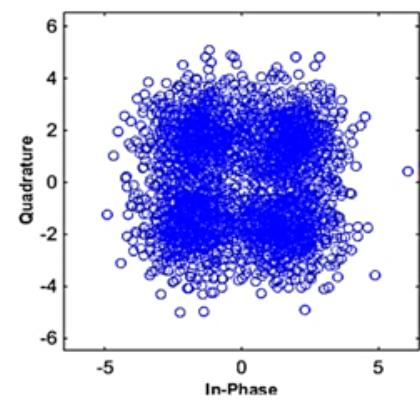

(a)

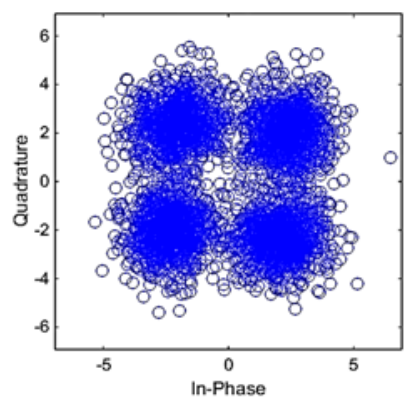

(b)

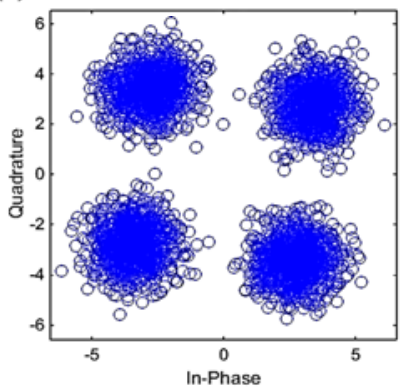

(c)

Fig. 11 CONSTELLATION DIAGRAM OF OOFDM SYSTEM AT THE RECEIVER END AFTER 900 KM AT (A) ORIGINAL (B) PROPOSED COMPANDING AT A=30 (C) PROPOSED COMPANDING AT A=87.6

\section{CONCLUSIONS}

The proposed system in this paper has confirmed a defeat of fiber nonlinearity using A-law companding in intensity modulation/direct detection optical orthogonal frequency division multiplexing system to decrease the PAPR value of OOFDM systems. The proposed technique implemented without any equalization technique or training sequence or any channel estimation. The results show that the parameter A at 87.6 is a best one to reduce the PAPR and performance improvement of BER, QF and spectral efficiency more than that of $A$ at 30 . All simulation results have been presented by combination VPI_Transmission_Maker software with the Matlab software package. In future, the system performance can be more improvement by proposing another PAPR technique with the A-law companding to make hybrid with adjustable value of $\mathrm{A}$.

\section{REFERENCES}

[1] Y. Ma, Q. Yang, Y. Tang, S. Chen, and W. Shieh, "1-Tb/s Single-Channel Coherent Optical OFDM Transmission With Orthogonal-Band Multiplexing and Subwavelength Bandwidth Access," Journal of Lightwave Technology, vol. 28, no. 4, pp. 308-315, 2010.

[2] J. Armstrong, "OFDM for optical communications," Journal of lightwave technology, vol. 27, no. 3, pp. 189-204, 2009.

[3] J. Zhou and Y. Qiao, "Low-PAPR Asymmetrically Clipped Optical OFDM for Intensity-Modulation/Direct-Detection Systems," IEEE Photonics Journal, vol. 7, no. 3, pp. 1-8, 2015.

[4] D. Agarwal, N. Sharan, M. P. Raja, and A. Agarwal, "PAPR reduction using precoding and companding techniques for OFDM systems," in 2015 International Conference on Advances in Computer Engineering and Applications, pp. 18-23, 2015.

[5] X. Zhang, P. Liu, J. Liu, and S. Liu, "Advanced A-law employing nonlinear distortion reduction in DCO-OFDM systems," in 2015 IEEE/CIC International Conference on Communications in China - Workshops (CIC/ICCC), pp. 184-188, 2015.

[6] D. Gupta and D. Dhawan, "A Study of Various PAPR Reduction Techniques for Optical OFDM Systems," International Journal of Computer Applications, vol. 115, no. 15, 2015.

[7] A. Alavi, C. Tellambura, and I. Fair, "PAPR reduction of OFDM signals using partial transmit sequence: an optimal approach using sphere decoding," IEEE Communications Letters, vol. 9, no. 11, pp. 982-984, 2005.

[8] R. W. Bauml, R. F. Fischer, and J. B. Huber, "Reducing the peak-to-average power ratio of multicarrier modulation by selected mapping," Electronics Letters, vol. 32, no. 22, pp. 2056-2057, 1996. 
[9] L. Maivan, J. He, M. Chen, F. Mangone, and L. Chen, "New hybrid peak-to-average power ratio reduction technique based on carrier interferometry codes and companding technique for optical direct-detection orthogonal frequency division multiplexing system," Optical Engineering, vol. 53, no. 8, p. 086104, 2014.

[10] J. Xiao, J. Yu, X. Li, Q. Tang, H. Chen, F. Li, et al., "Hadamard transform combined with companding transform technique for PAPR reduction in an optical direct-detection OFDM system," IEEE/OSA Journal of Optical Communications and Networking, vol. 4, no. 10, pp. 709-714, 2012.

[11] F. Mangone, J. He, J. Tang, J. Xiao, M. Chen, F. Li, et al., "A PAPR reduction technique using Hadamard transform combined with clipping and filtering based on DCT/IDCT for IM/DD optical OFDM systems," Optical Fiber Technology, vol. 20, no. 4, pp. 384-390, 2014.

[12] Z. Xiaojing, L. Peng, L. Jiang, and L. Song, "An advanced A-law companding algorithm in VLC-OFDM," in 2014 IEEE 3rd Global Conference on Consumer Electronics (GCCE), pp. 721-722, 2014.

[13] T. Sravanti and N. Vasantha, "PAPR reduction in OFDM using reduced complexity PTS with companding," in 2017 Third International Conference on Advances in Electrical, Electronics, Information, Communication, and BioInformatics (AEEICB), pp. 371-374, 2017.

[14] W. Shieh, Q. Yang, and Y. Ma, "107 Gb/s coherent optical OFDM transmission over 1000-km SSMF fiber using orthogonal band multiplexing," Optics Express, vol. 16, no. 9, pp. 6378-6386, 2008.

[15] M. Chang-Po and K. Ji-Wen, "Orthogonal Frequency Division Multiplex with Multi-Level Technology in Optical Storage Application," Japanese Journal of Applied Physics, vol. 43, no. 7S, p. 4876, 2004. 